\title{
A Study on Tensile Strain Distribution and Fracture Coordinate of Nanofiber Mat by Digital Image Correlation System
}

\author{
Nak Gyu Park ${ }^{1}$, Kyung Min Hong ${ }^{2, *(1)}$ and Kyu Hyeung Kwon ${ }^{3}$ \\ 1 Division of Mechanical Design Engineering, Jeonbuk National University, Jeonju-si, \\ Jeollabuk-do 54896, Korea; parker2920@jbnu.ac.kr \\ 2 Division of Electronics Engineering, Jeonbuk National University, Jeonju-si, Jeollabuk-do 54896, Korea \\ 3 Innotems Corp., Techno 1-ro, Yuseong-gu, Daejeon 34015, Korea; yjkang@jbnu.ac.kr \\ * Correspondence: hkm775@jbnu.ac.kr; Tel.: +82-63-270-2453
}

Received: 1 August 2020; Accepted: 28 August 2020; Published: 29 August 2020

check for updates

\begin{abstract}
Strain gauges are commonly used for tension tests to obtain the strain of a metal test specimen. They make contact, however, so the gauges are not applicable to every type of test specimen. That is the reason why a non-contact type measurement system is required. Nanofibrous mats, manufactured by electrospinning, have different structures and thicknesses. Displacement and strain distributions for all ranges of the specimen have never been demonstrated for nanofiber mats so far. Wrinkled nanofibrous mats of polyurethane were made and then tension-tested. The Digital Image Correlation (DIC) method was employed to measure displacement, then to calculate strain for all areas of the specimen. The DIC system consisted of a CMOS camera, control PC and operating software with a DIC algorithm: then, the Center of Gravity (COG) algorithm was used for this system. A cross-head speed of $3 \mathrm{~mm} / \mathrm{min}$ was set for the tension test. The image record speed was one frame a second. In total, 400 image frames were obtained from the start, and then displacement and strain distributions were acquired for a 400 second tension test. The strain distribution from DIC system showed good agreement with the test result by a universal testing machine.
\end{abstract}

Keywords: digital image correlation; nanofiber mat; tension test; strain distribution

\section{Introduction}

Nano technology has been improved in the field of energy, environment, electricity and medical science for several decades. A manufacturing technology to produce fibers under several hundred nanometers has been used-for example, by filtering, battery or fuel cell separators, tissue engineering, and drug delivery system [1-6]. Mechanical property assessments of the nanofibers, such as yield strength or strain, should be required for optimal use of them. It is not easy to prepare mechanical test specimens from nanofibers under a few hundred nanometers, because they are very weak at very small forces. Thus, most of the mechanical test specimens should be obtained from fibrous mats. Each nanofiber property was evaluated by quantitative analysis comparison with nanofiber mat mechanical properties [7-11]. Petterson et al. introduced mechanical models of nonwoven fabrics with unit cells and fiber directions [12]. Hearle and Stevenson proposed a theory to evaluate the elastic modulus of nonwoven fabrics by fiber direction effect on fabric strain [13]. Different mechanical test results may be caused by mat fiber density, porosity, and specimen dimensions. Therefore, the displacement and strain of the mat should be measured through testing the surface of the specimen for the mechanical property evaluation of nanofiber mats.

The DIC method is a non-contact measurement technique which demonstrates displacement and strain distributions of a test specimen with time by acquiring a reference image and deformed image 
and then analyzing the correlation between the two images. The precision level in the measurement was low and it took a long time to compute, due to the poor computer and camera capacities in the first step of DIC development [14]. However, there has been a remarkable enhancement in computer and camera technologies over recent decades, so the DIC method has become one an alternative systems to contact-type measurement systems. In addition, portable measurement devices with DIC systems is possible because of its simple constitution with only a digital camera, computer for control, and operating algorithm $[15,16]$. It is possible to apply this system to video or image recording systems, such as Computed Tomography (CT), an X-ray, or a Scanning Electron Microscope (SEM). Therefore, a new non-contact displacement and strain measurement system with DIC technique was proposed to evaluate the mechanical properties of such a non-uniform material as nanofiber mat in this research.

\section{Digital Image Correlation (DIC) System}

The following processes should be executed to acquire the displacement and strain of a material by applied force per unit time with Digital Image Correlation (DIC) method: (1) The reference image should be obtained and should not be deformed; (2) deformed image should be taken; (3) digital image correlation coefficients should be determined between two images to use for brightness distribution; (4) displacement and strain should be computed with position data of (by) the DIC coefficient results. The minimum unit of brightness distribution for correlation comparison is called subset image [17]. The size of subset image is $(2 n+1)$ by $(2 n+1)$ of square shape. The reference subset image is the image separated from reference image, and the deformed subset image is the image separated from the deformed image. The center of reference subset image is the tracking position for material displacement. The same deformed subset image to reference subset image is determined by finding out the highest correlation coefficient between two reference and deformed subset images, which is comparison iteration. If determined by computation, the distance between two centers of those images should be the displacement of specimen deformation by applied force. Additionally, the displacement vector is calculated by the coordinates of two centers and, finally, the displacement and strain of material are driven by several equations. Figure 1 shows the basic measurement principle of the DIC.
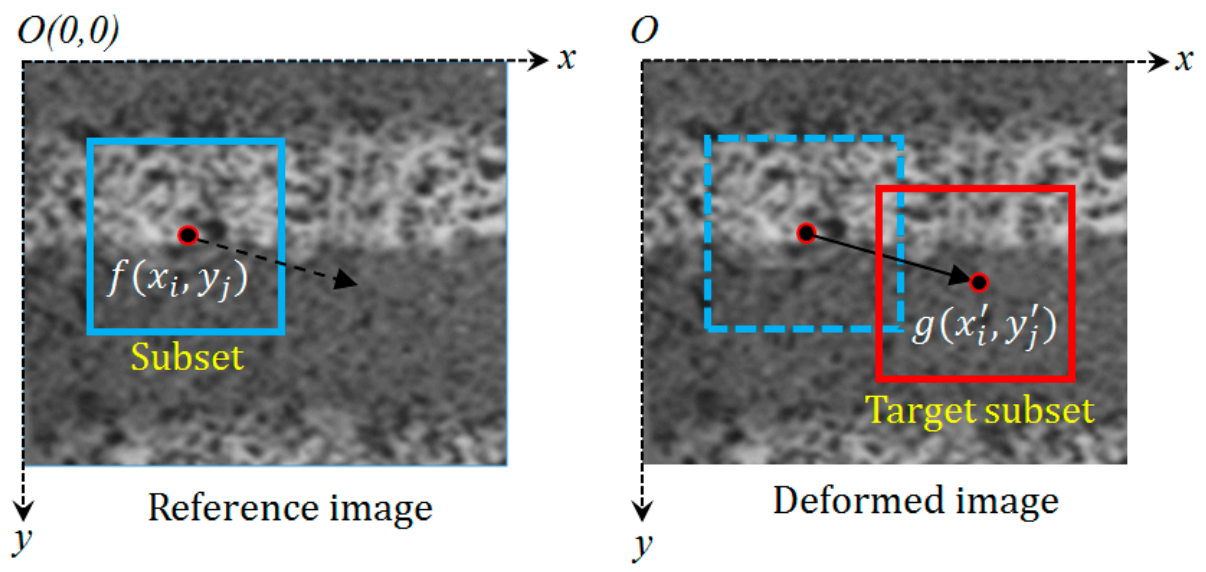

Figure 1. The principle of measuring the displacement by using the digital image correlation method.

There are two methods to analyze the image correlation: one is to use the cross-correlation (CC) criterion, and the other is to apply the sum of squared differences (SSD) criterion. These methods measure the brightness values of spots on the image for analysis $[18,19]$. The CC criterion uses the maximum value of the highest correlation from the calculation. In contrast, the SSD criterion uses the minimum value of the highest correlation [20-22]. Table 1 shows commonly used cross-correlation criteria and their definitions, and Table 2 shows those for the sum of squared differences criteria. Two more equations can be adopted for each criterion by averaging or normalizing the brightness 
distribution. The equations for zero-normalized cross-correlation (ZNCC) and zero-normalized sum of squared differences (ZNSSD) have a mutual conversion.

Table 1. Commonly used cross-correlation (CC) criteria and their definitions (M: natural number).

\begin{tabular}{cc}
\hline CC Correlation Criterion & Definition \\
\hline Cross-correlation (CC) & $C_{C C}\left(x_{i}, y_{j}, x_{i}^{\prime}, y_{j}^{\prime}\right)=\sum_{i=-M}^{M} \sum_{j=-M}^{M}\left[f\left(x_{i}, y_{j}\right) g\left(x_{i}^{\prime}, y_{j}^{\prime}\right)\right]$ \\
Normalized cross-correlation (NCC) & $C_{N C C}\left(x_{i}, y_{j}, x_{i}^{\prime}, y_{j}^{\prime}\right)=\sum_{i=-M}^{M} \sum_{j=-M}^{M}\left[\frac{f\left(x_{i}, y_{j}\right) g\left(x_{i}^{\prime}, y_{j}^{\prime}\right)}{\bar{f} \bar{g}}\right]$ \\
$\begin{array}{c}\text { Zero-normalized cross-correlation } \\
\text { (ZNCC) }\end{array}$ & $C_{Z N C C}\left(x_{i}, y_{j}, x_{i}^{\prime}, y_{j}^{\prime}\right)=\sum_{i=-M}^{M} \sum_{j=-M}^{M} \frac{\left[f\left(x_{i}, y_{j}\right)-f_{m}\right]\left[g\left(x_{i}^{\prime}, y_{j}^{\prime}\right)-g_{m}\right]}{\Delta f \Delta g}$ \\
\hline
\end{tabular}

Table 2. Commonly used sum of squared differences correlation (SSD) criteria and their definitions.

\begin{tabular}{cc}
\hline SSD Correlation Criterion & Definition \\
\hline $\begin{array}{c}\text { Normalized } \\
\text { Sum of squared differences (SSD) }\end{array}$ & $C_{S S D}\left(x_{i}, y_{j}, x_{i}^{\prime}, y_{j}^{\prime}\right)=\sum_{i=-M}^{M} \sum_{j=-M}^{M}\left[f\left(x_{i}, y_{j}\right)-g\left(x_{i}^{\prime}, y_{j}^{\prime}\right)\right]^{2}$ \\
sum of squared differences (NSSD) & $C_{N S S D}\left(x_{i}, y_{j}, x_{i}^{\prime}, y_{j}^{\prime}\right)=\sum_{i=-M}^{M} \sum_{j=-M}^{M}\left[\frac{f\left(x_{i}, y_{j}\right)}{\bar{f}}-\frac{g\left(x_{i}^{\prime}, y_{j}^{\prime}\right)}{\bar{g}}\right]^{2}$ \\
$\begin{array}{c}\text { Zero-normalized sum of squared } \\
\text { differences (ZNSSD) }\end{array}$ & $C_{Z N S S D}\left(x_{i}, y_{j}, x_{i}^{\prime}, y_{j}^{\prime}\right)=\sum_{i=-M}^{M} \sum_{j=-M}^{M}\left[\frac{f\left(x_{i}, y_{j}\right)-f_{m}}{\Delta f}-\frac{g\left(x_{i}^{\prime}, y_{j}^{\prime}\right)-g_{m}}{\Delta g}\right]^{2}$ \\
\hline
\end{tabular}

where

$$
\begin{gathered}
f_{m}=\frac{1}{(2 M+1)^{2}} \sum_{i=-M}^{M} \sum_{j=-M}^{M} f\left(x_{i}, y_{j}\right) \\
g_{m}=\frac{1}{(2 M+1)^{2}} \sum_{i=-M}^{M} \sum_{j=-M}^{M} g\left(x_{i}^{\prime}, y_{j}^{\prime}\right) \\
\bar{f}=\sqrt{\sum_{i=-M}^{M} \sum_{j=-M}^{M} f\left(x_{i}, y_{j}\right)^{2}} \\
\bar{g}=\sqrt{\sum_{i=-M}^{M} \sum_{j=-M}^{M} g\left(x_{i}^{\prime}, y_{j}^{\prime}\right)^{2}} \\
\Delta f=\sqrt{\sum_{i=-M}^{M} \sum_{j=-M}^{M}\left[f\left(x_{i}, y_{j}\right)-f_{m}\right]^{2}} \\
\Delta g=\sqrt{\sum_{i=-M}^{M} \sum_{j=-M}^{M}\left[g\left(x_{i}^{\prime}, y_{j}^{\prime}\right)-g_{m}\right]^{2}}
\end{gathered}
$$

\section{DIC Algorithm Configuration for Nanofiber Mat and Application Test}

The conventional DIC system has difficulty in tracking the image after deformation when the strain rate is relatively large, as in the tensile test of the fiber mat material. Therefore, we developed an analysis algorithm, as follows, to increase the calculating speed and image traceability.

\subsection{Image Correlation Method by using Fast Fourier Transform (FFT)}

The conventional image correlation method uses a reference subset image as a kernel. Convolutions are operated from initial guess area for reference subset image coordinates based on image change. The strain is calculated by the coordinate change detection, which is the highest coordinate for correlation. Every coordinate in reference and all deformed images must be compared and calculated 
to obtain accurate displacement positions, so this process requires a lot of iterations. Thus, this conventional DIC method needs quite a long time to measure. However, the FFT-based DIC method compares the correlation from reference subset images to deformed subset images along the frequency range. That means that the initial guess does not need to be determined, and it also does not need iterations. It is possible to analyze DIC even faster than the conventional method. Figure 2 is the matrix calculation diagram to obtain $\mathrm{C}_{\mathrm{ZNCC}}$ correlation criteria by the FFT method.

$$
C_{\mathrm{ZNCC}}=\frac{\sum_{i} \overline{R_{l} T_{l}}}{\sum_{i}\left(\overline{R_{l}}\right)^{2} \sum_{i}\left(\overline{T_{l}}\right)^{2}}
$$

where $\overline{R_{l}}=R_{i}-R_{m}$ and $\overline{T_{l}}=T_{i}-T_{m}$, with $R_{m}$ and $T_{m}$ as the mean values of the intensity in the two subsets-i.e., $R_{m}=1 / N \sum_{i} R_{i}$ and $T_{m}=1 / N \sum_{i} T_{i}$. Notice that the superscript * has been omitted here, since $R$ contains only real numbers and thus, $R *(x)=R(x) . R \otimes T=F T^{-1}\left\{[F T(R)]^{*} \cdot F T(T)\right\}$, where $F T(\cdot)$ and $F T^{-1}(\cdot)$ denote the Fourier transform and inverse Fourier transform, respectively.

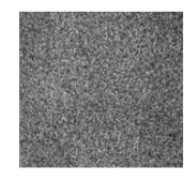

Reference subset

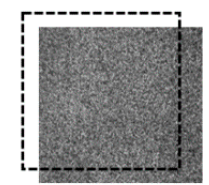

Target subset

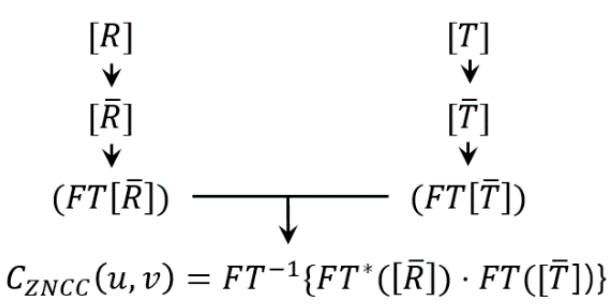

Figure 2. The correlation comparison procedure with FFT images.

\subsection{FFT-Based Image Correlation Measurement Algorithm by using Displacement Feedback Loop}

Displacement change in material continuously influences the adjacent area for the deformation by applied force. This change increases along the axis of applied force. Thus, the DIC method needs to expect the maximum displacement of initial guess area and then applies to every tracing point. The initial guess area is widened due to the large deformation of material, which is time consuming as the iterations of image analysis increase.

Figure 3 shows the displacement variation of the solid material by a uniaxial load. Material deformation is not dependent on each position but on adjacent area, because material is a continuum. This changes along the same direction of applied load, as mentioned above. Therefore, the same amount of deformation $(\beta)$ is assumed for the same length $(\alpha)$ by a uniaxial load: then, Equation (8), as follows, is obtained.

$$
\begin{gathered}
X_{1}^{\prime \prime}=X_{0}+\alpha+\beta=X_{1}^{\prime}+\beta \\
X_{2}^{\prime \prime}=X_{1}^{\prime \prime}+\alpha+\beta=X_{1}^{\prime}+\alpha+2 \beta=X_{0}+2(\alpha+\beta) \\
\cdots \\
X_{n}^{\prime \prime}=X_{n-1}^{\prime \prime}+\alpha+\beta=X_{n-1}^{\prime}+\alpha+2 \beta=X_{0}+n(\alpha+\beta)
\end{gathered}
$$

The conventional DIC method specifies the initial guess area based on displacement tracing position from reference image subset. The value of initial guess area should be set over $2 \beta$, which represents material deformation because the value of initial guess position is set on $X_{n}$ position. Finally, the initial guess area becomes wider at a further position from $X_{0}$, which is set as the origin. 


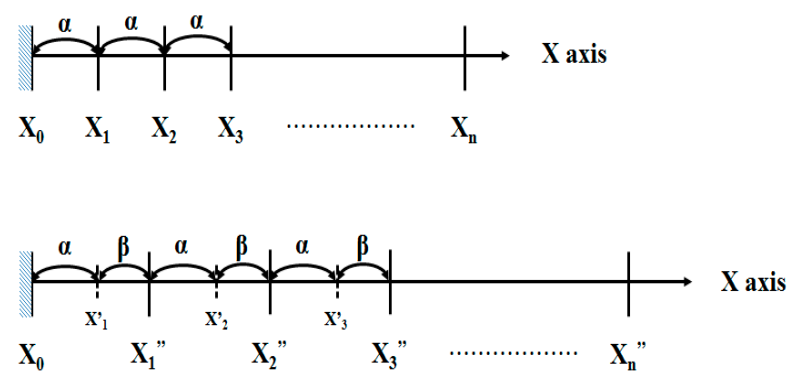

Figure 3. The displacement variation of the solid material by a uniaxial load.

When the subset image to be analyzed is separated from the reference image, the FFT region area can be much reduced by updating the measured strain value. The following algorithm was established for FFT DIC. The algorithm, shown in Figure 4, applies a double feedback loop to FFT DIC-the image analysis result around the adjacent region is applied to the next result of deformed images in the feedback. The first displacement measurement is done to the next initial guess area in the same way. Because the amount of displacement is small for each image, the upper left-side initial guess area can be set small. Thus, the small initial guess area size is conserved, regardless of local deformation, and finally, a faster strain measurement is made because the area is small.

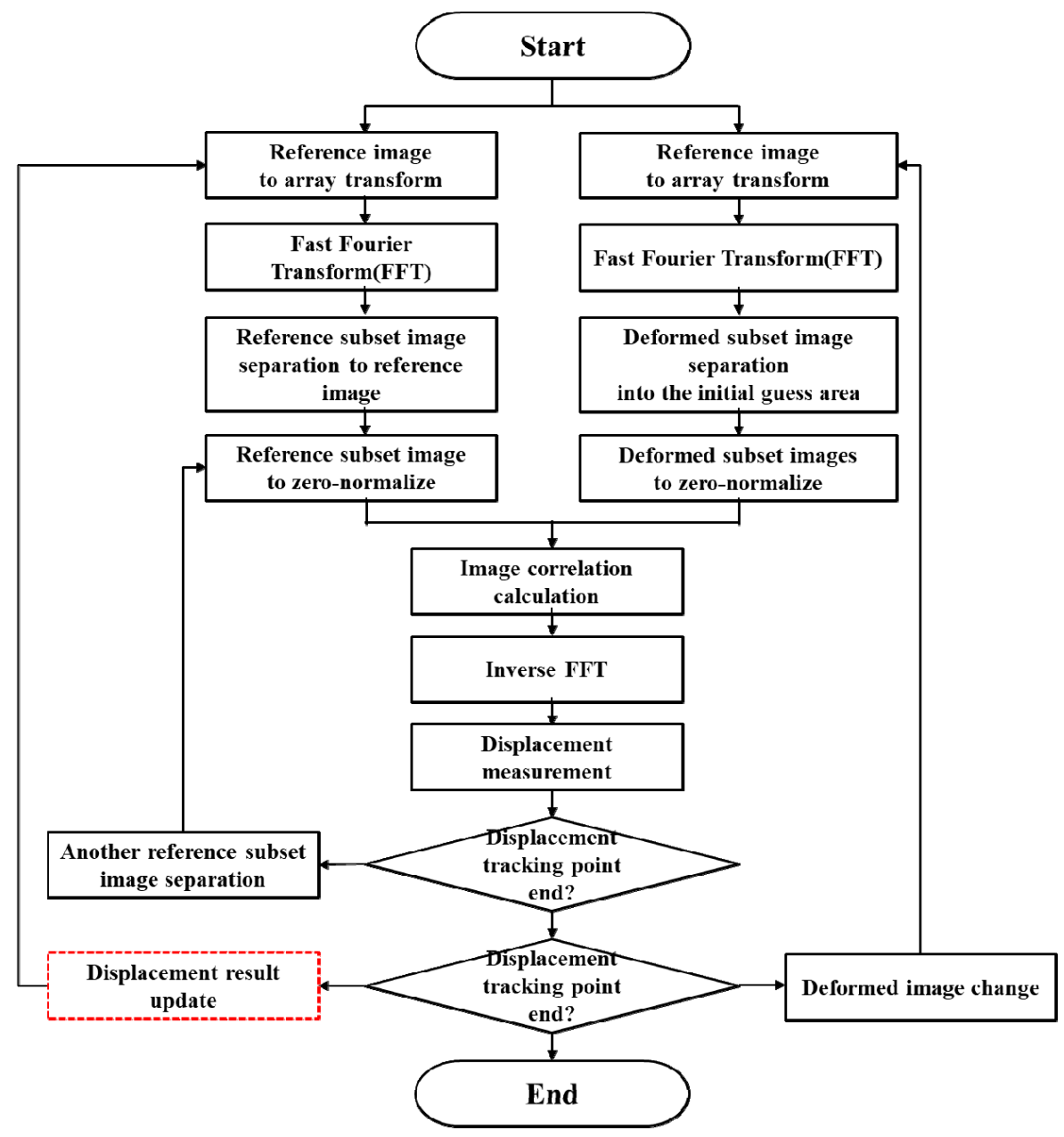

Figure 4. The optimization of the initial guess area size to reduce the calculation of the image correlation between the reference image and the deformed image for the auto captured images by using FFT, based on the digital image correlation measurement devices. (Red-dot box: added displacement feedback process). 


\subsection{Algorithm Test for Metal Specimen}

Aluminum specimens were used for the tensile tension test. The extensometer was attached to the specimen to measure its displacement. The strain measurement system for DIC analysis was equipped in front of a universal testing machine to take pictures of the deforming specimen. The focal distance of the strain measurement sensor was controlled to obtain the same result from the extensometer. The cross-head speed was $1 \mathrm{~mm} / \mathrm{min}$. The frequency at which the measured data from the extensometer were obtained was once a second, and that from the DIC analysis system was also the same. Figure 5 shows the size of the aluminum specimen, and Figure 6 is a photograph of experimenting with the system we developed.
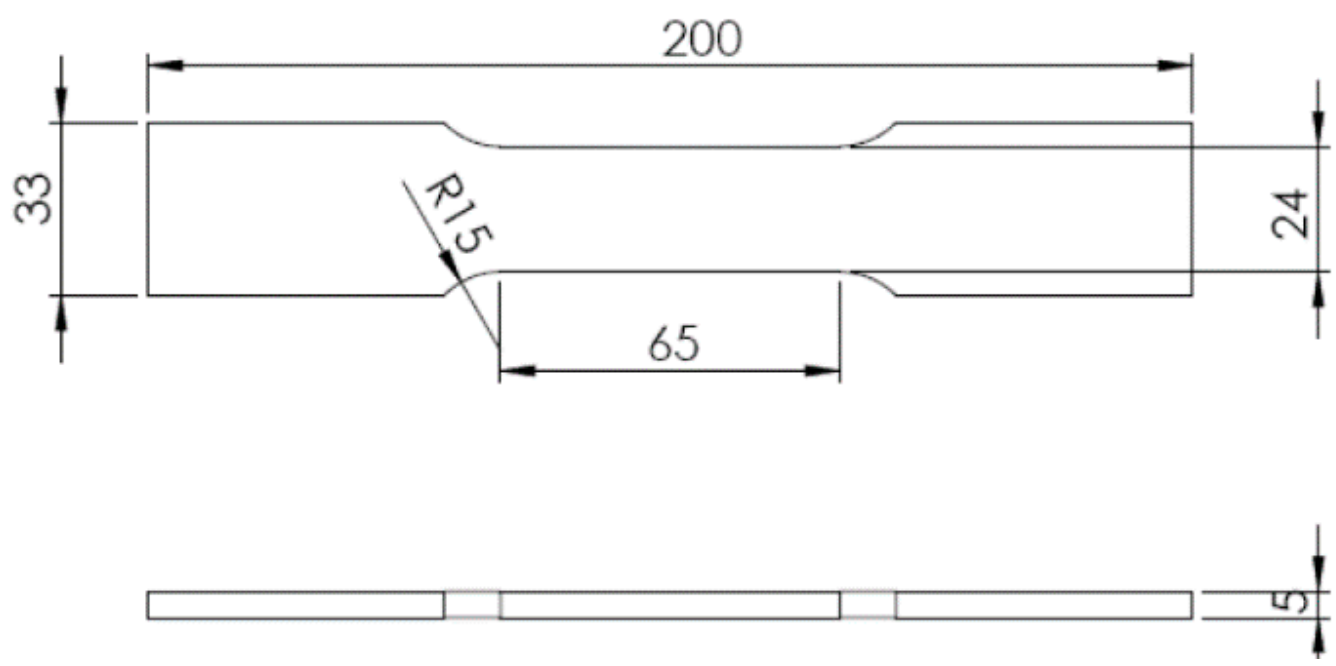

Figure 5. The schematic diagram of test specimen (aluminum6061-T6, mm).

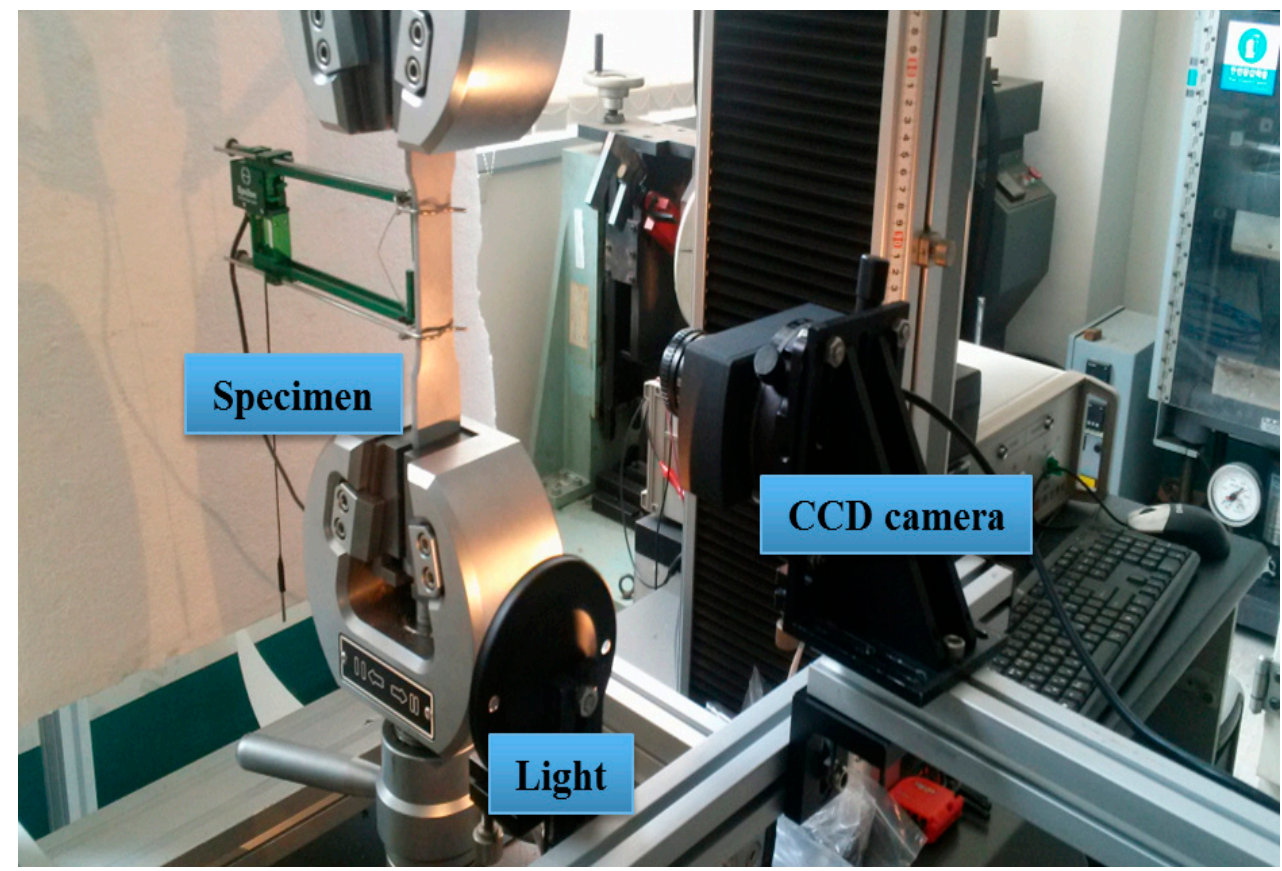

Figure 6. Photography of the tensile test using the universal test machine and DIC system.

Figure 7 shows the strain-stress curve from the load cell and extensometer data. Two kinds of calculated results were compared with each other from the conventional DIC system and our new feedback-added FFT DIC system. The images of $x$-deformation and y-deformation were analyzed to 
compare the two different methods. The images of the 100th, 200th, 300th, 400th, 500th and 600th frames were analyzed as follows. One frame of the image was saved per second. Thus, the shown images are from the start of the process to 10 minutes. The following images are not for the whole size of the specimen, but for the interest area of 6916 pixel points, which is composed of a width of 52 pixels and a height of 133 pixels.

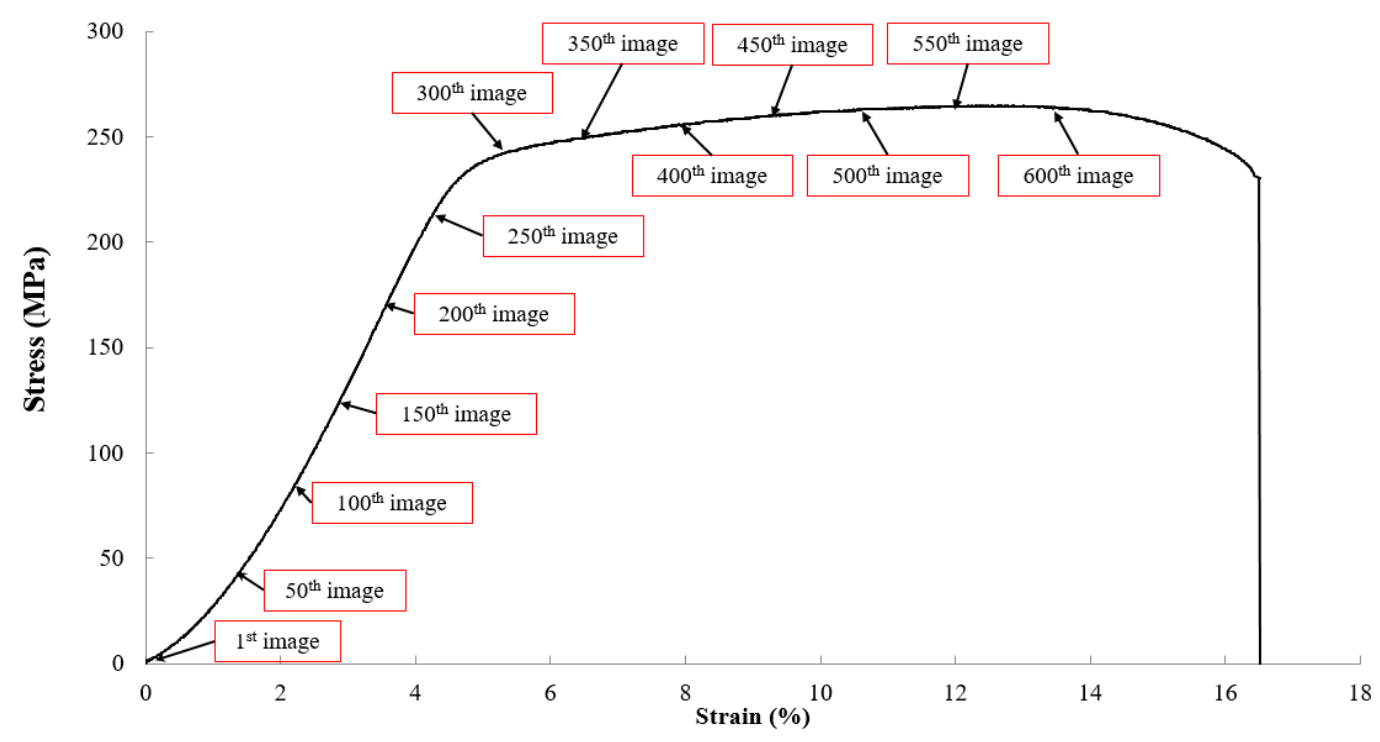

Figure 7. Strain-stress curve from the load cell and extensometer data.

The images from (e) to (f) in Figure 8 show it was impossible to trace the correlation point with higher strain for conventional DIC analysis. This is because the measurable displacement range is limited by subset image size when conventional DIC analysis is used. The image (e) in Figure 8 shows that there was inner defect or facture, despite there being no defect or fracture in and on the specimen. The system failed to track the upper region of image (f) after (e). The images in Figure 9 show the displacement distribution along the $X$ and $Y$ directions with our new feedback with added FFT DIC analysis. The maximum displacement was larger than the subset image size. In addition, there were no image errors. Because pre-process was added to measure displacement by using a 20 by 20 subset image size to the new analysis method, then this displacement result was provided as feedback for the extracted image coordinate of the deformed region. Therefore, our new analysis system demonstrated larger strain measurement for material deformation because the feedback algorithm was added, regardless of subset image size.
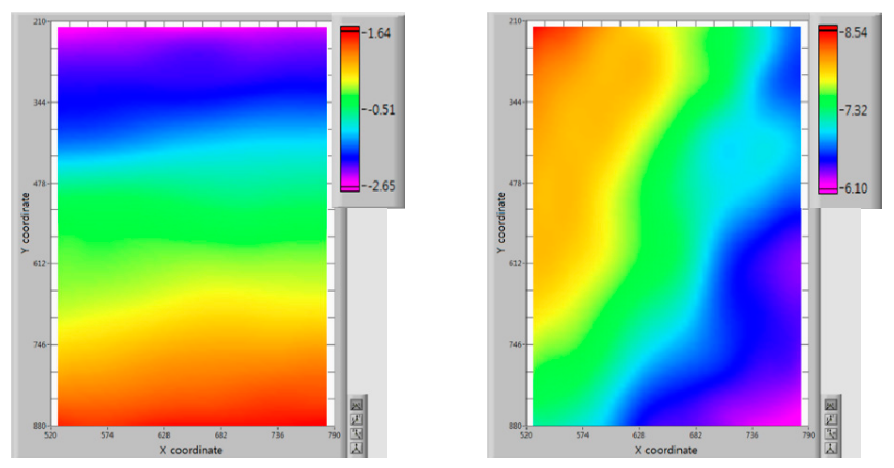

(a) 100th

Figure 8. Cont. 

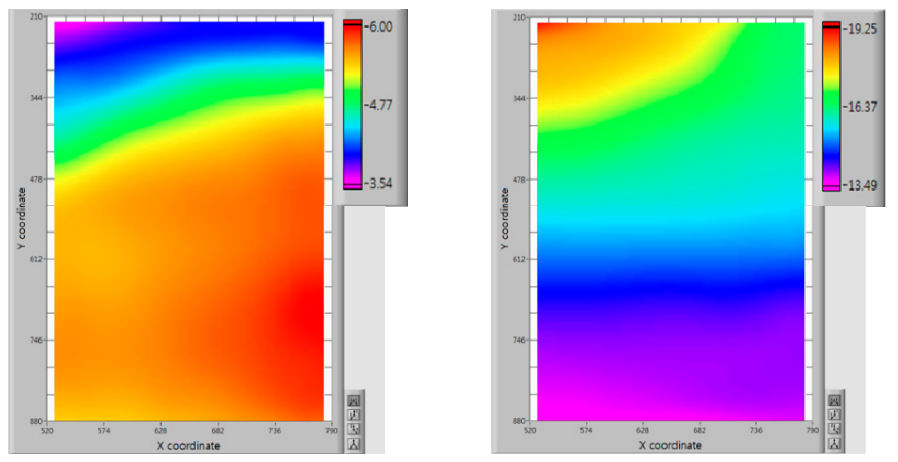

(b) 200th
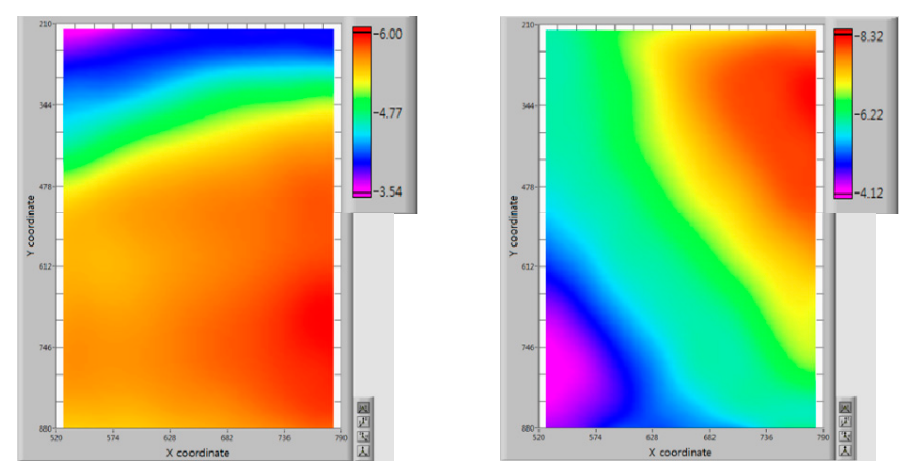

(c) $300 \mathrm{th}$
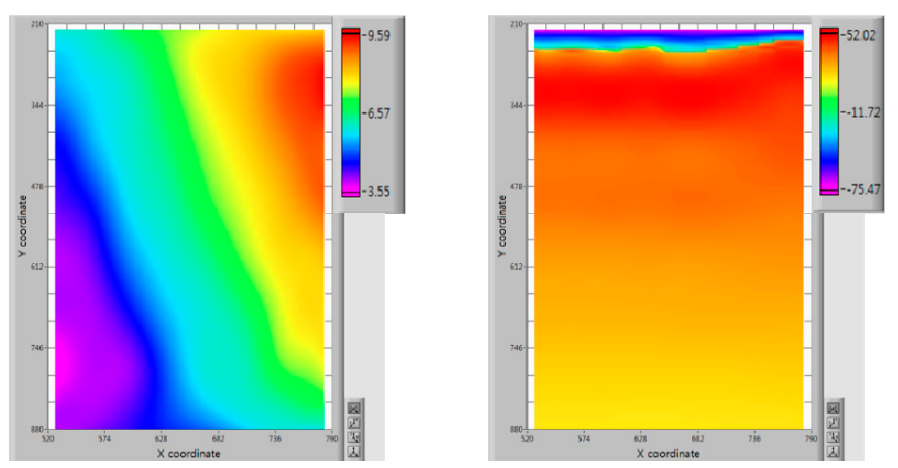

(d) 400th
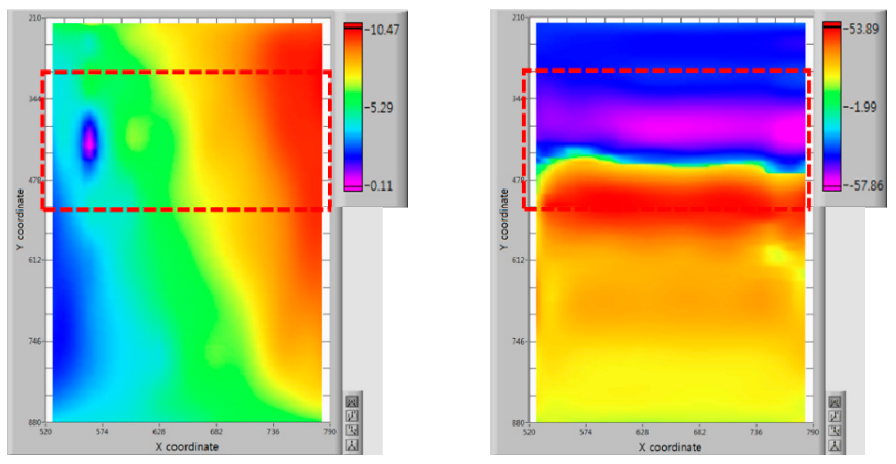

(e) $500 \mathrm{th}$

Figure 8. Cont. 

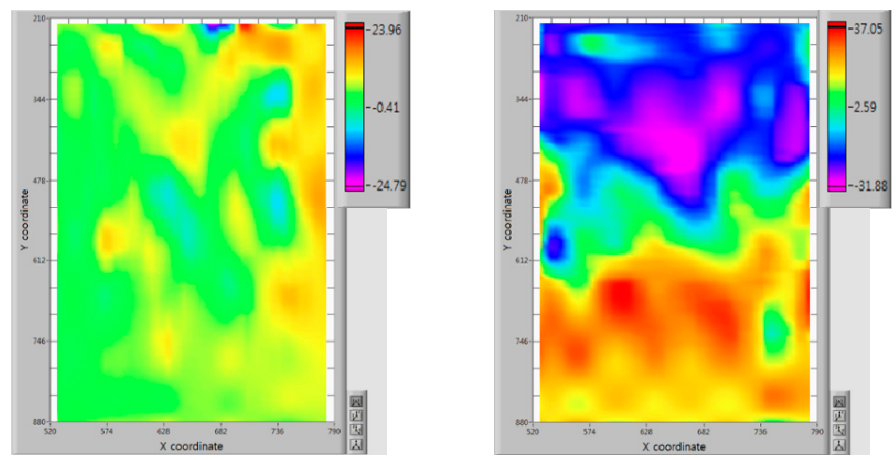

(f) 600th

Figure 8. The results of displacements distribution by the conventional DIC algorithm. (Left: x-direction, Right: y-direction deformation result).
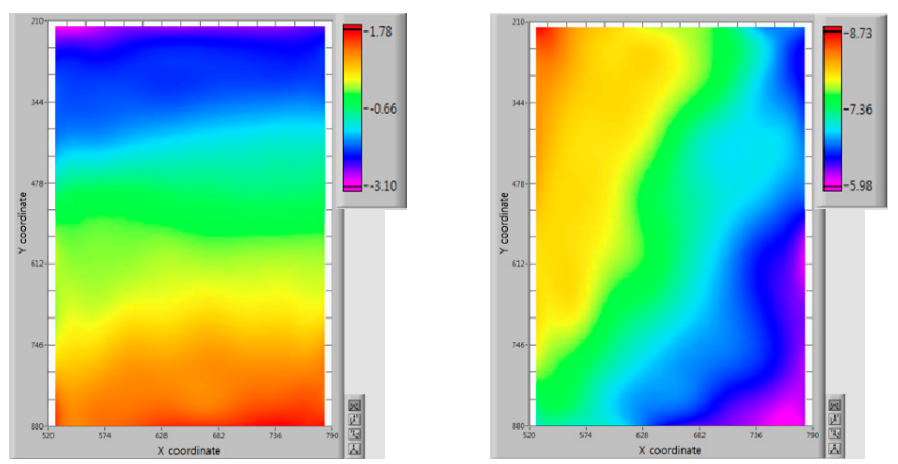

(a) 100th
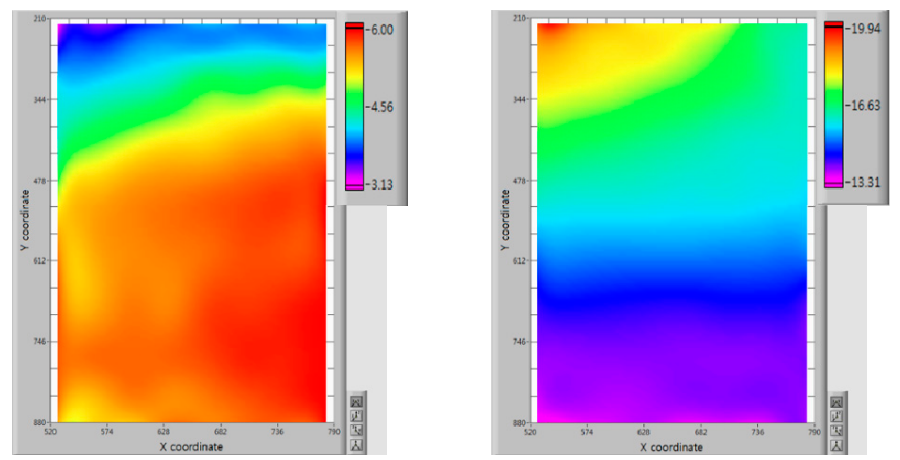

(b) 200th
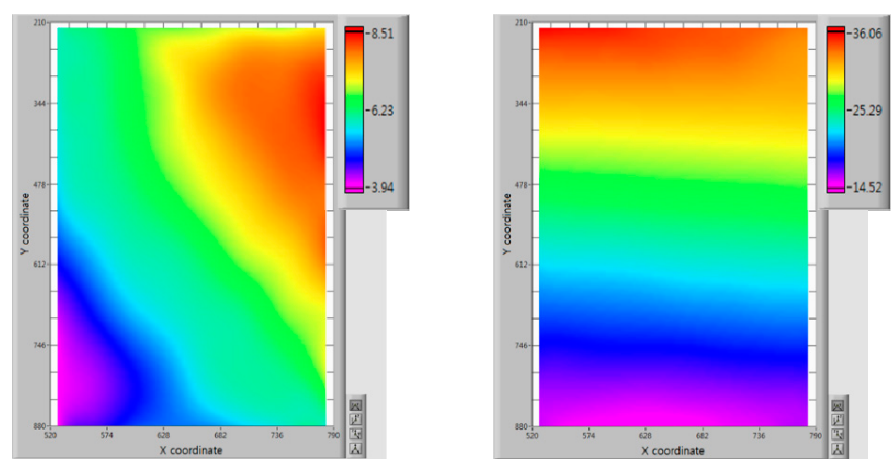

(c) $300 \mathrm{th}$

Figure 9. Cont. 

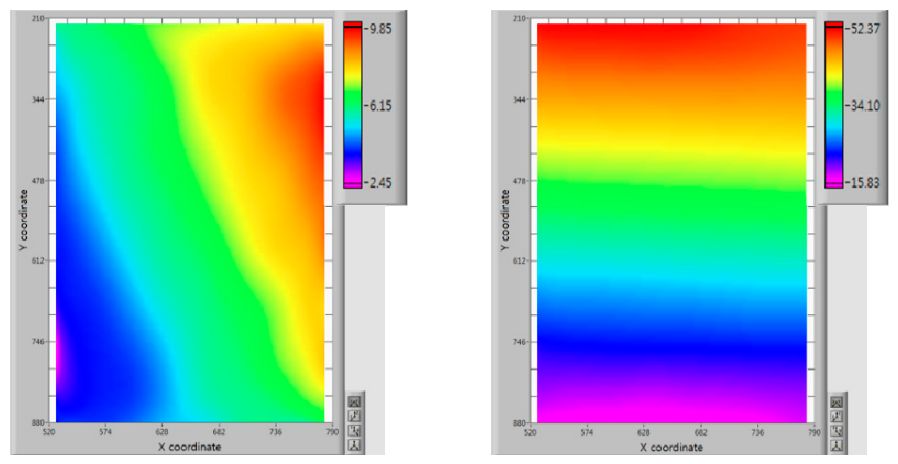

(d) 400 th
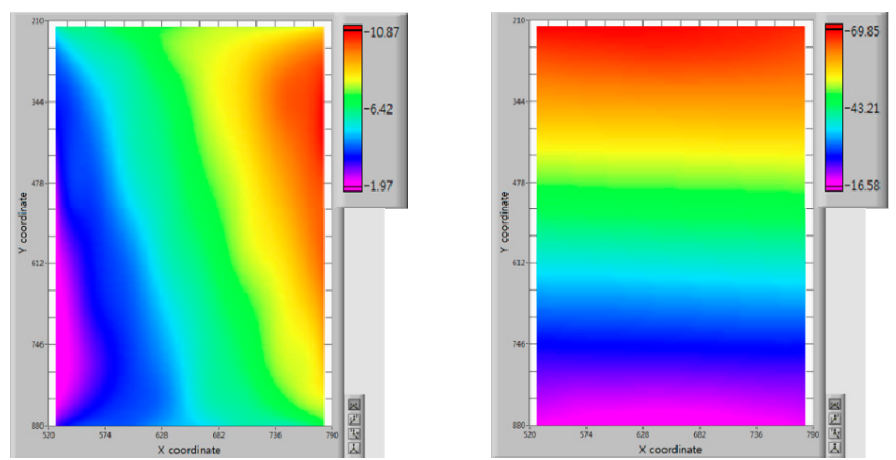

(e) 500 th
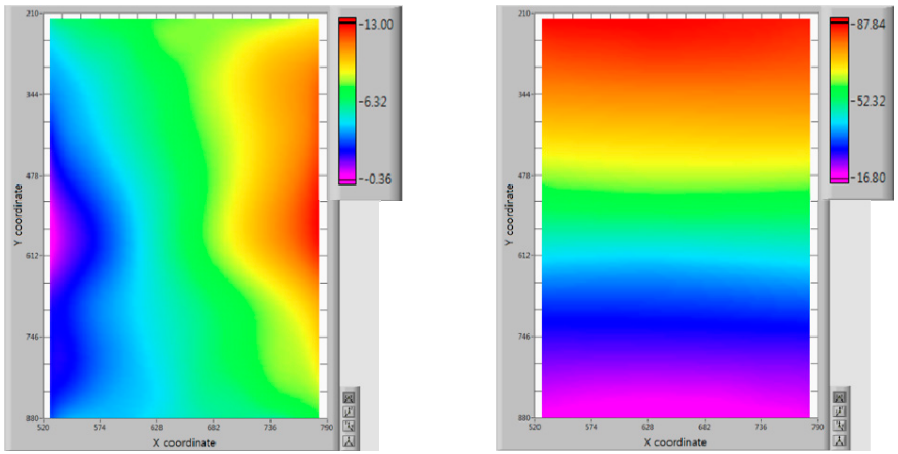

(f) 600 th

Figure 9. The results of displacements distribution by the newly configured FFT DIC algorithm. (Left: x-direction, Right: y-direction deformation result).

\section{Wrinkled Nanofiber Mat by Electrospinning}

There are various methods to manufacture nanofibers, such as drawing, template synthesis, phase separation, self-assembly, electrospinning and so on. Electrospinning is one of the most widely used methods to manufacture continuous nanofibers. Figure 10 shows the schematic diagram of electrospinning for this research. This system consists of positive potential nozzle parts, which spray polymer solution and negative potential collector parts. A high voltage between nozzle and collector parts is charged so that the solution is emitted, and the nanofiber manufactured if the force by electric field between the two parts exceeds the surface tension of the solution. Two main factors of polymer solution properties and manufacturing conditions influence nanofiber formation for electrospinning. For example, polymer solution properties are molecular structure, viscosity, elasticity, conductivity, induced electricity and so on. Manufacturing conditions are the magnitude of electric field, working distance between nozzle and collector, feed rate of solution, temperature and so on. In general, the spun 
nanofibers have a randomly spread structure of networking. In this paper, the heterogenous material structure of a manufactured nanofiber mat was selected for the displacement and strain demonstration. This was composed of two types of fiber structures for increase in non-uniformity: one was networking (white) and the other was arranged (dark) in Figure 11.

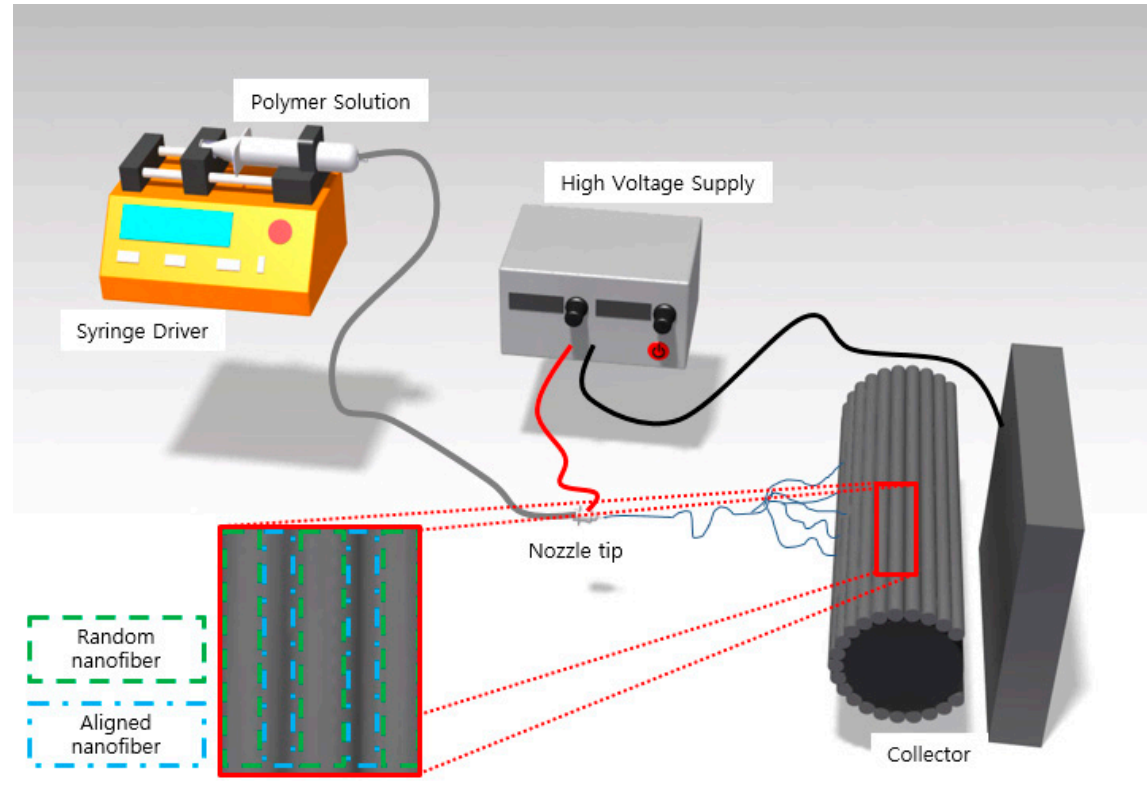

Figure 10. The schematic diagram for fabricating nanofiber mat.

Table 3 shows the operating conditions for electrospinning of the polyurethane nanofiber mat, and Figure 11 illustrates these conditions.

Table 3. Summarized conditions of electrospinning.

\begin{tabular}{ccccc}
\hline Polymer & Concentration & Spinning Feed Rate & Input Voltage & Spinning Time \\
\hline polyurethane & $10 \mathrm{wt} \%$ & $1 \mathrm{~mL} / \mathrm{h}$ & $12 \mathrm{kV}$ & $3 \mathrm{~h}$ \\
\hline
\end{tabular}

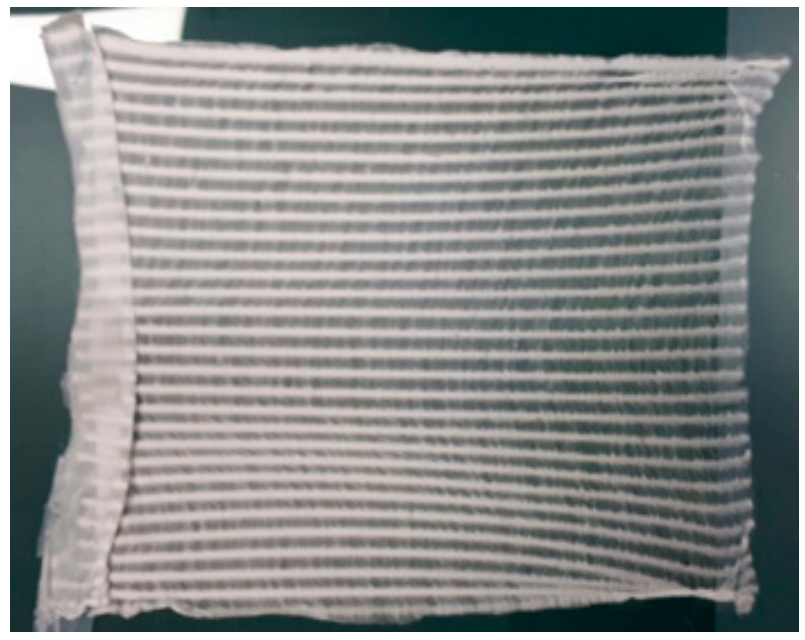

Figure 11. The photograph of a fabricated nanofiber mat. 


\section{Experiment}

\subsection{Experimental Configuration}

Figure 12 shows the measurement system configuration for tension test, and universal testing machine was used. The DIC system obtained image data of specimen deformation from the camera during the tensile test. The specimen dimensions for the fabricated nanofiber mat are shown in Figure 13. The setting region of interest on the captured images allows for saving analysis time by eliminating unnecessary regions, because the DIC system analyzes the total area of the pictures. The cross-head speed of the testing machine was maintained at $3 \mathrm{~mm} / \mathrm{min}$ of tension. The resolution of the load cell used in the experiment was $0.001 \mathrm{~N}$, and it was sufficient to measure the deformation of the nanofiber mat specimen. Force and displacement were measured every second. A maximum force of $0.085 \mathrm{~N}$ was applied for about $7 \mathrm{~min}$ during the tensile test.

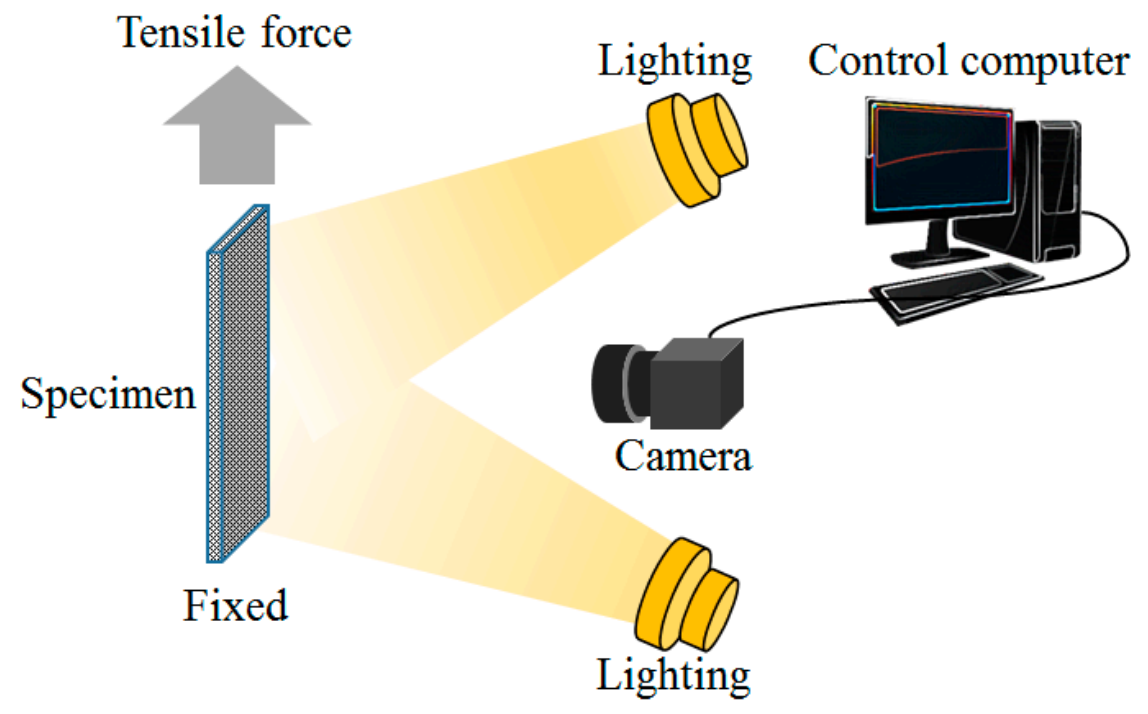

Figure 12. Schematic diagram of experimental setup.

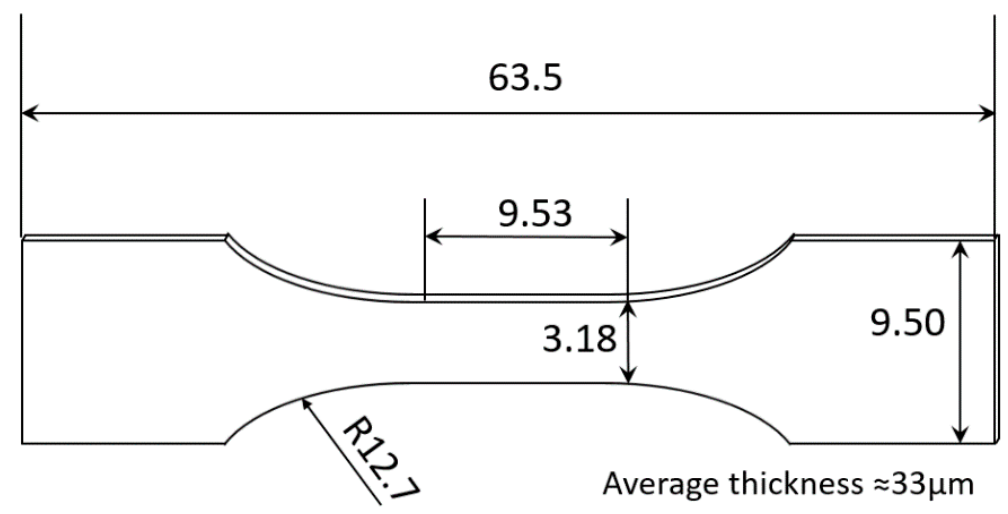

Figure 13. The dimension of test specimen (mm).

Images were saved every one second. This means that the deformation between one second may be observed and then shown in a 2-dimensional distribution image. In addition, it is easy to separate specific time ranges or a specific area. Nine strain distributions for the $y$-direction, corresponding to the strain-stress curve from the load cell distance change of the two grips at crosshead and load frame, were demonstrated after calculating the strains. Table 4 shows the specification of the universal testing machine and Table 5 shows the specification of the digital camera in this test. 
Table 4. Specification of universal test machine.

\begin{tabular}{cccccc}
\hline Manufacturer & Model & $\begin{array}{c}\text { Capacity } \\
(\mathbf{k g f})\end{array}$ & $\begin{array}{c}\text { Min. Speed } \\
(\mathbf{m m} / \mathbf{m i n})\end{array}$ & $\begin{array}{c}\text { Max. Speed } \\
(\mathbf{m m} / \mathbf{m i n})\end{array}$ & $\begin{array}{c}\text { Resolution } \\
(\boldsymbol{\mu m})\end{array}$ \\
\hline MTDI & UT-020 & 2000 & 0.0005 & 1200 & 0.25 \\
\hline
\end{tabular}

Table 5. Specification of the digital camera using the digital image correlation system.

\begin{tabular}{cccc}
\hline Manufacturer & Model & Resolution & Image Sensor Type \\
\hline Lumenera & $\begin{array}{c}\text { LW } 115(12-\text { bit } \\
\text { color })\end{array}$ & $1280 \times 1024$ & CMOS \\
\hline
\end{tabular}

\subsection{Experimental Results}

Figure 14 is the strain-stress curve from two measurement systems; one is the DIC measurement and the other is the universal testing machine with the load cell. This test specimen was elongated continuously before the fracture. Testing the machine gave the strain data by calculating the following equation:

$$
(\text { Strain, } \%)=(\text { displacement }) /(\text { gage length }) \times 100
$$

The gage length of the test specimen was $7.62 \mathrm{~mm}$, but the extensometer for nanofibrous specimen could not be attached. Therefore, the strain results may include at least the narrow section length of $9.53 \mathrm{~mm}$. In addition, this heterogeneous specimen involved the arranged sections which should elongate more random sections, as shown in Figure 11. That is the reason why the strain results were overestimated. On the contrary, the DIC measurement technique can measure the accurate gage length by defining the height of the ROI with the same length. The green line reached about $272 \%$ of strain just before the fracture; however, the red line did not come to around $88 \%$ strain. In other words, the strain was exaggerated by three times at maximum elongation.

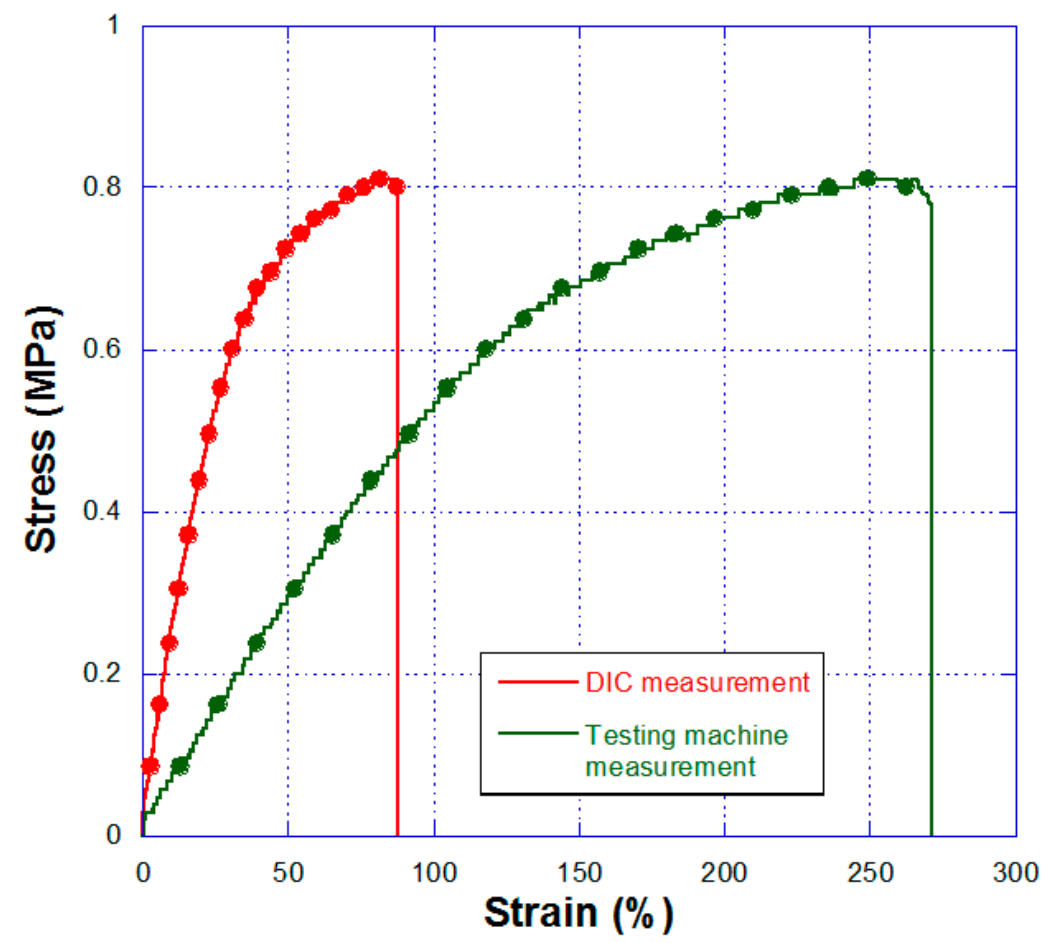

Figure 14. Tensile test results of the nanofiber mat specimen for DIC and testing machine measurements (red and green dots: measurement points by $20 \mathrm{~s}$ ). 
The displacement distributions in tension direction (that is y-direction) from DIC analysis are shown in Figure 15. Each displacement distribution was obtained after calculating the correlation coefficient between reference image and deformed image by DIC algorithm. Nine distributions were those of the 1st, 50th, 100th, 150th, 200th, 250th, 300th, 350th and 400th analysis results. Additionally, these nine points were marked on the strain-stress curve in Figure 14. The $X$ and $Y$ coordinates were the acquired image pixel coordinates for vertical and horizontal directions, respectively. The region of interest (ROI) had a rectangular area 43 pixels wide and 315 pixels high. The gage length of the specimen was $7.62 \mathrm{~mm}$, corresponding to 315 pixels, so that each pixel represented $24.2 \mu \mathrm{m}$. Each distribution shows a higher value in upper position and a lower value in lower position, because the lower position of test specimen was fixed and upper position of that was moved upward. The first distribution shows the displacement of about 0.1 pixel, corresponding to $2.42 \mu \mathrm{m}$. The 50th has the maximum value of about $920 \mu \mathrm{m}$-this displacement value increased with time to about $8.93 \mathrm{~mm}$ before fracture at the 400th. The displacement distributions from the 50th to 400th were divided into four or six regions by color, because the nanofiber mat had not only a randomly arranged area but also a uniformly arranged area, repeatedly. The uniformly arranged area shows high displacement, which is brighter than the regions in the random area, while the randomly arranged area has low displacement in the line profile of Figure 16.

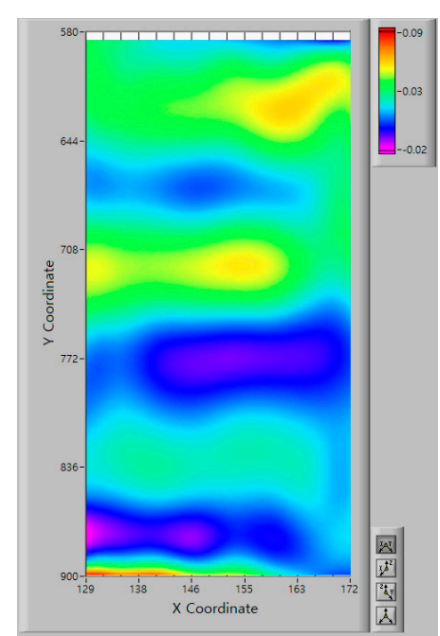

(a) $1 \mathrm{st}$

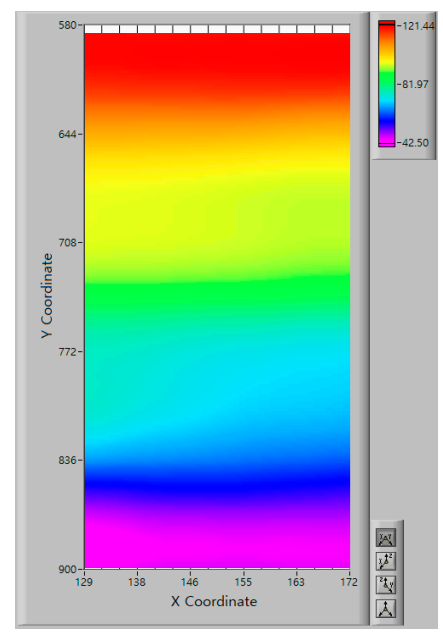

(d) 150th

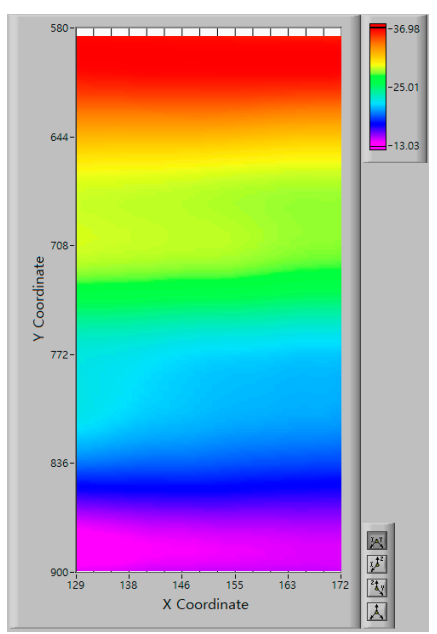

(b) 50th

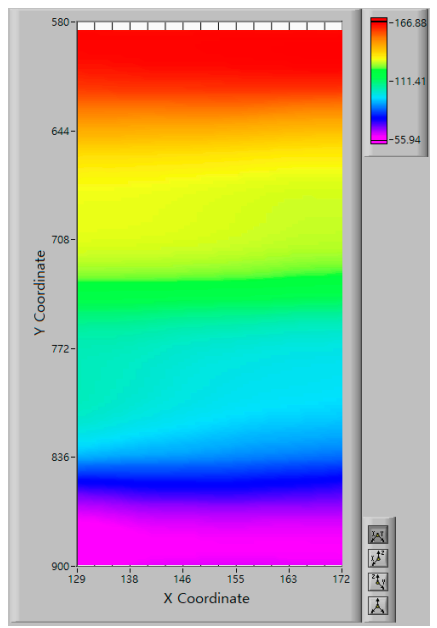

(e) 200th

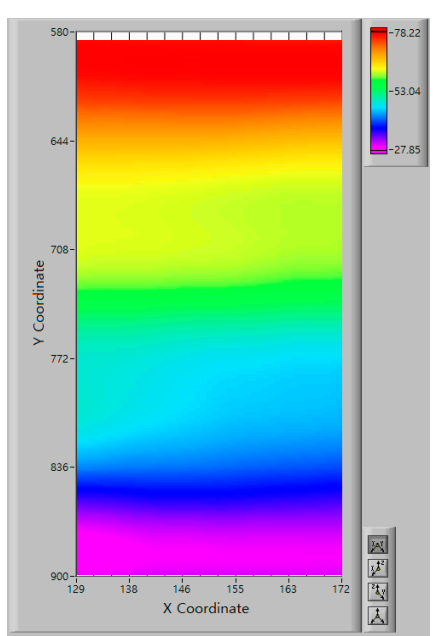

(c) 100 th

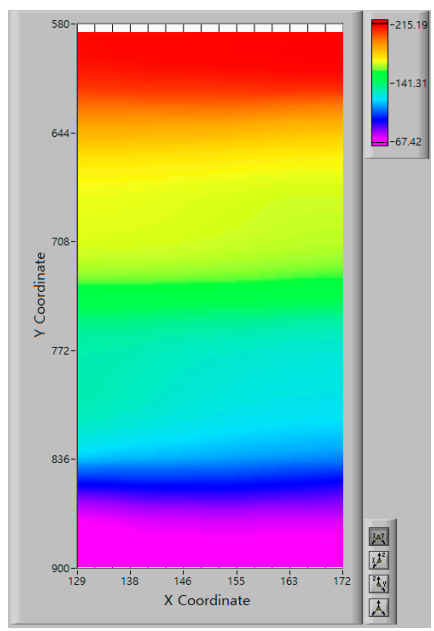

(f) 250 th

Figure 15. Cont. 


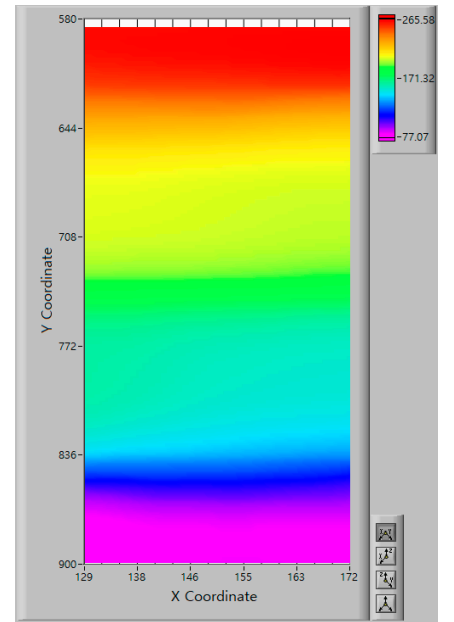

(g) 300th

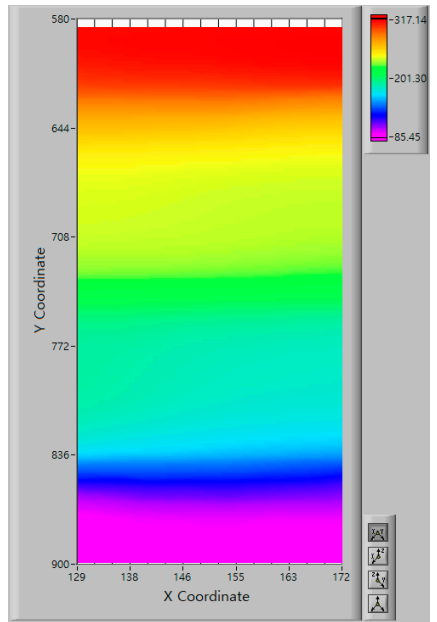

(h) 350 th

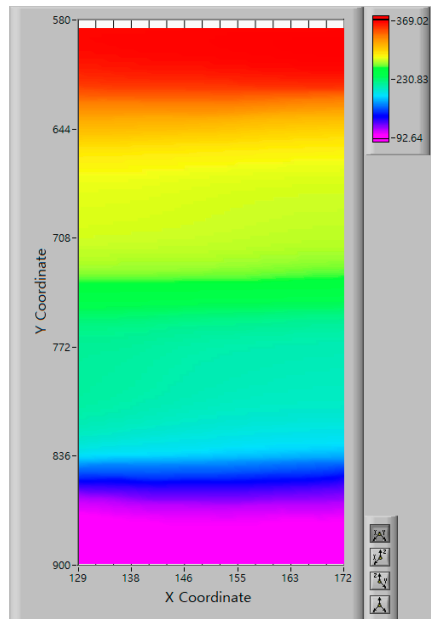

(i) 400 th

Figure 15. Y direction displacement distributions from DIC measurement.

\section{Deformation value (pixel)}

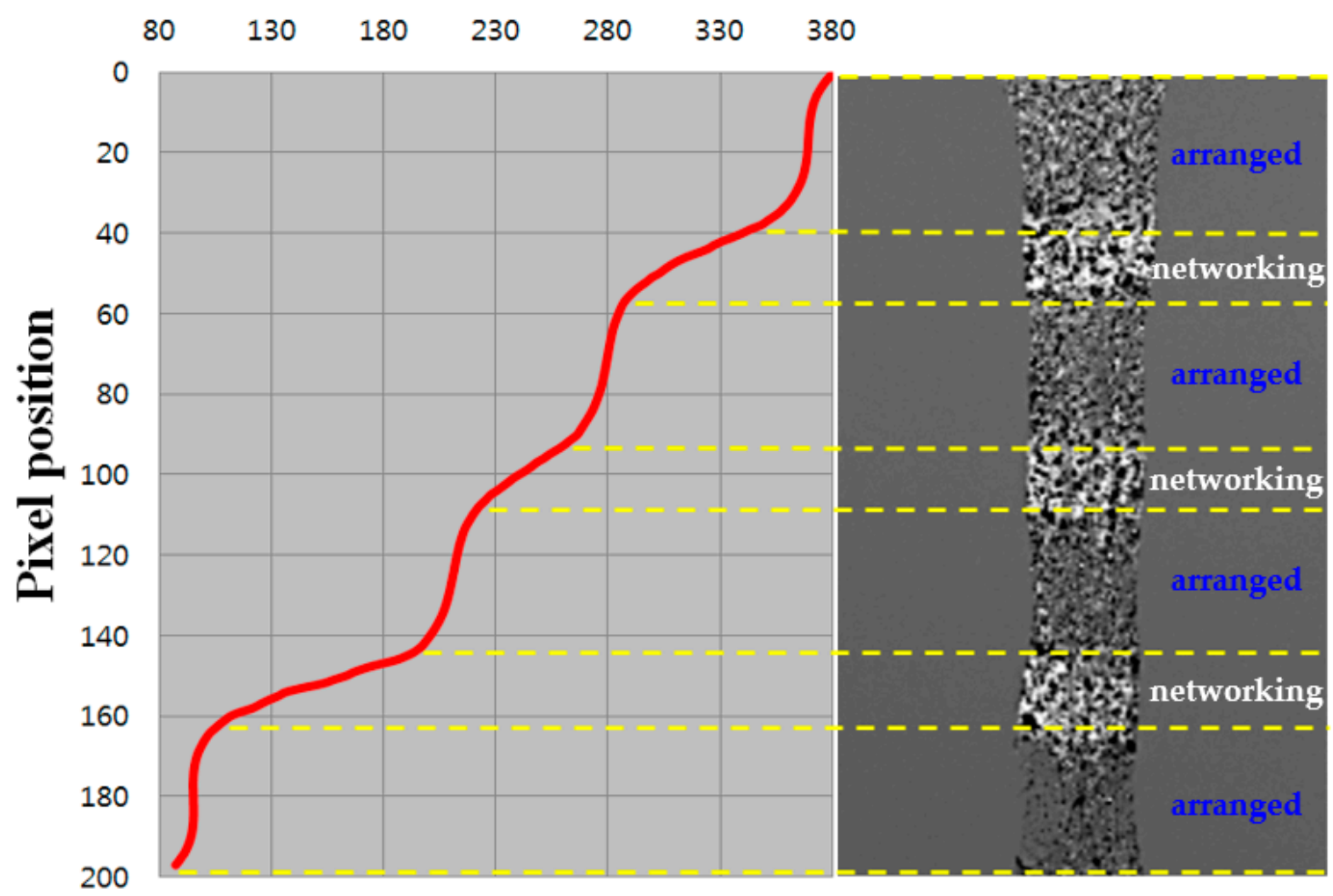

Figure 16. The displacement profile in the y-direction (left) and original image (right) at 400th image: random network part (white) and arranged part (dark) on the right.

The strain distributions from calculation, based on the displacement distributions, are shown in Figure 17. Separated regions are obvious by the repeated pattern of the random-uniform arrangement of nanofibers. 


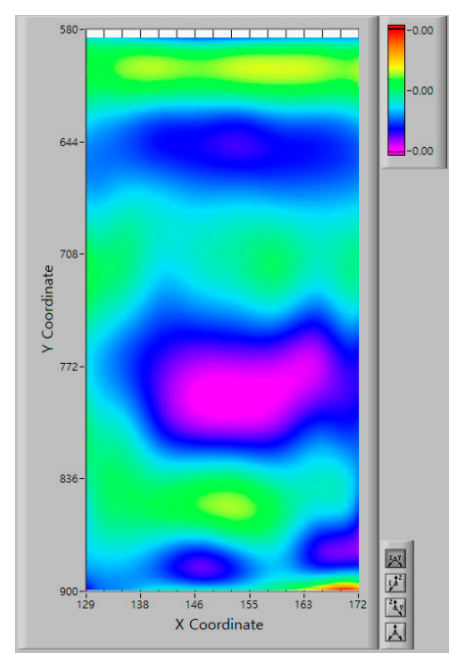

(a) 1 st

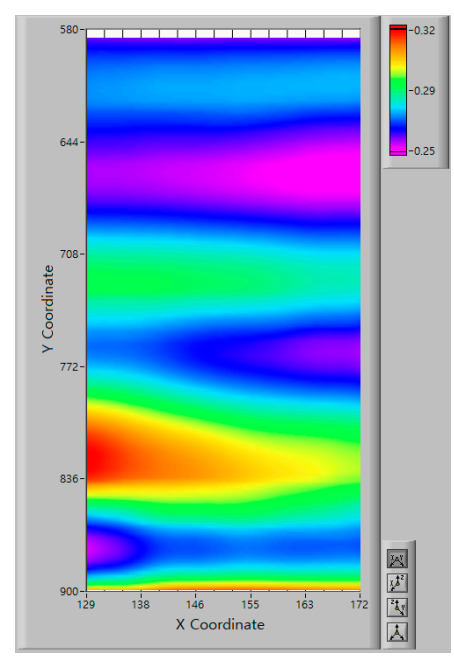

(d) 150 th

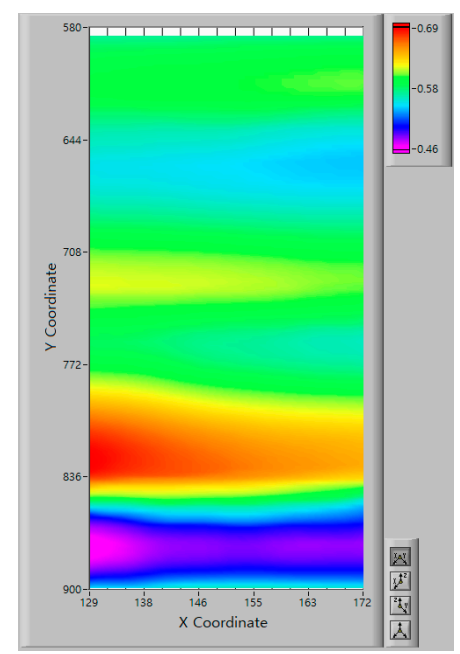

(g) 300th

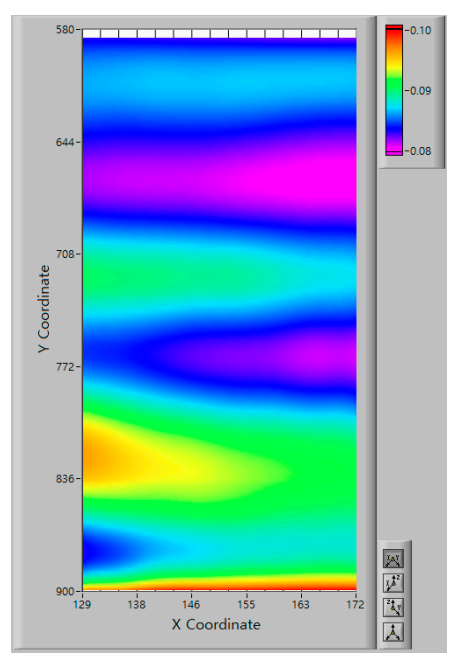

(b) 50th

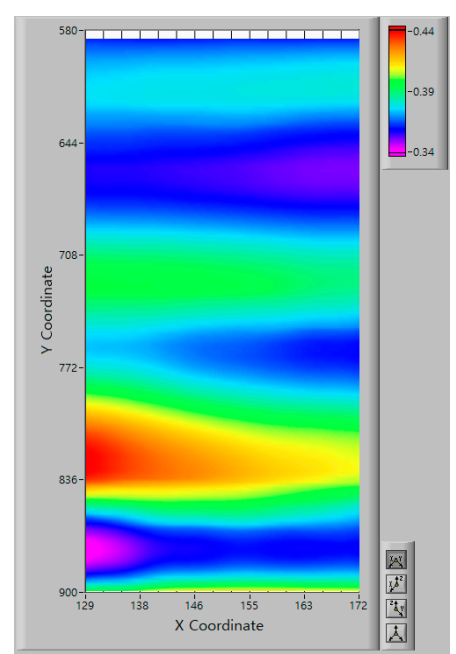

(e) 200th

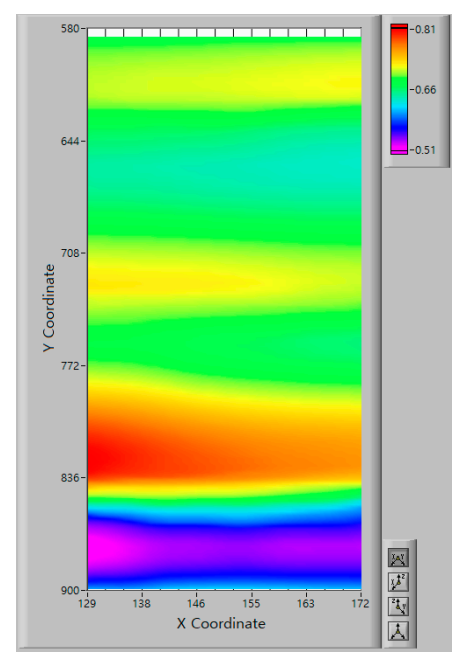

(h) 350th

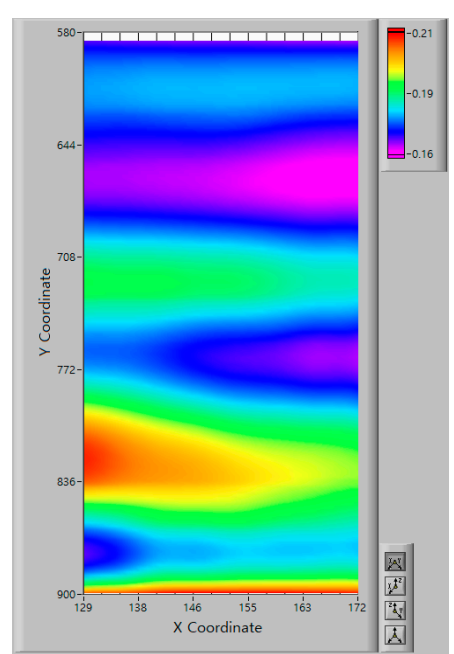

(c) 100th

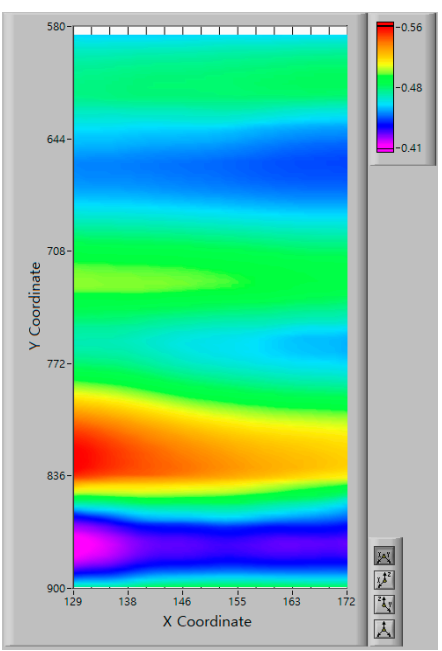

(f) 250 th

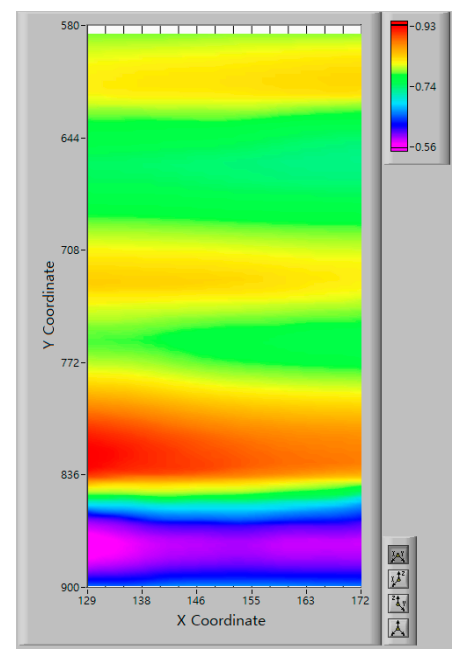

(i) 400th

Figure 17. Y-direction strain distributions from DIC measurement.

There is an easy way to detect the weakest part of the specimen. There must be the maximum displacement at the weakest section. So, the displacement gradients along the $\mathrm{Y}$ direction were 
calculated and are shown in Figure 18. Another ROI, 47 pixels wide and 394 pixels high, was used to show the displacement gradient distribution for the broadened area. Eight figures $(b-i)$ reveal that longer displacement parts were located at the arranged sections of the nanofibrous tensile specimen.

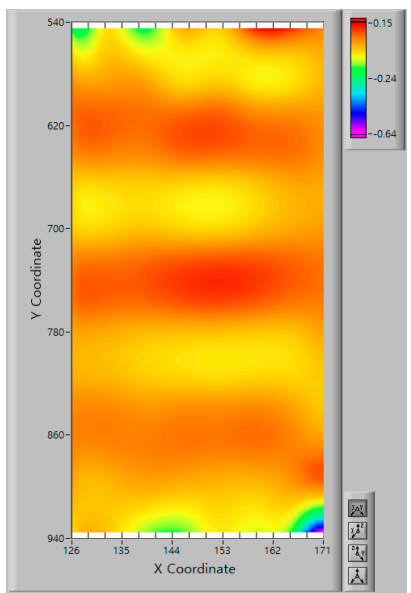

(a) 1 st

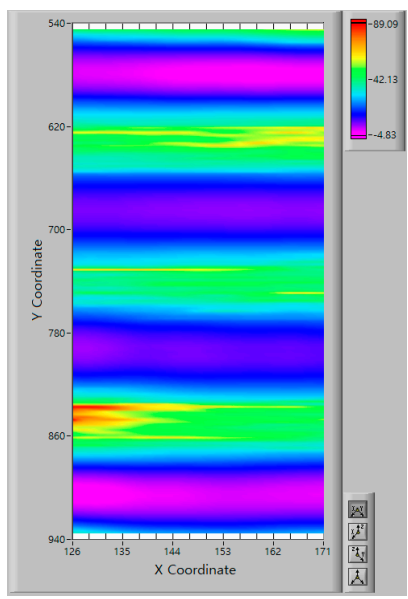

(d) 150 th

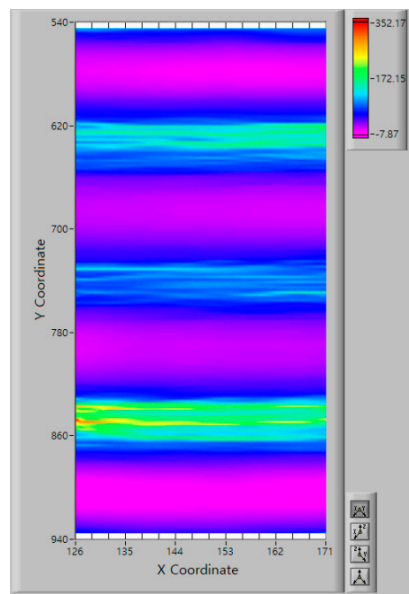

(g) 300th

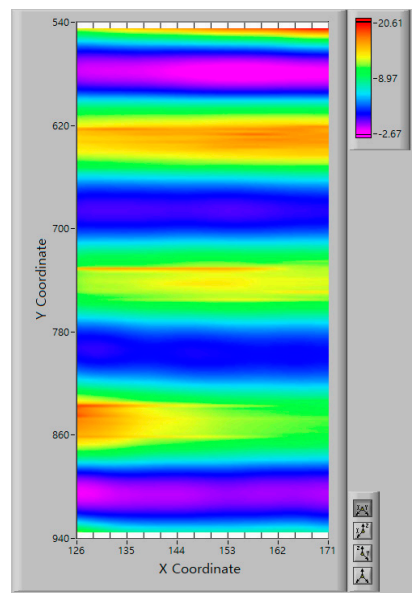

(b) 50 th

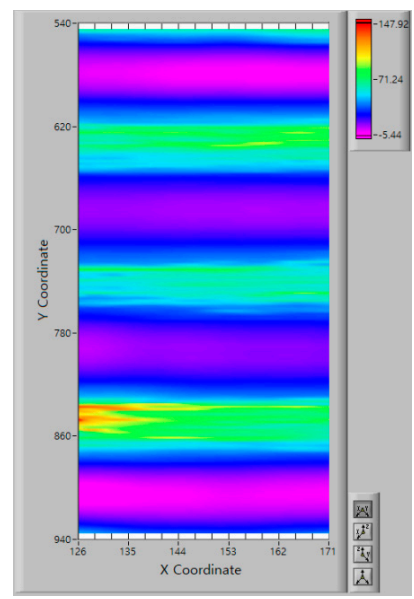

(e) 200th

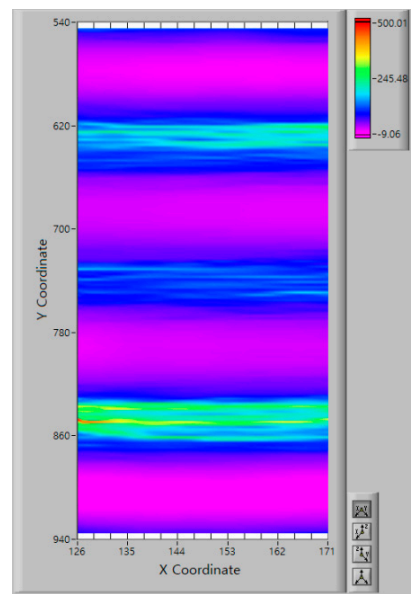

(h) 350 th

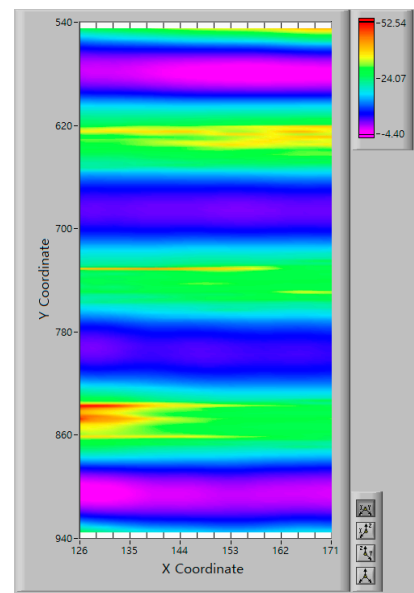

(c) 100th

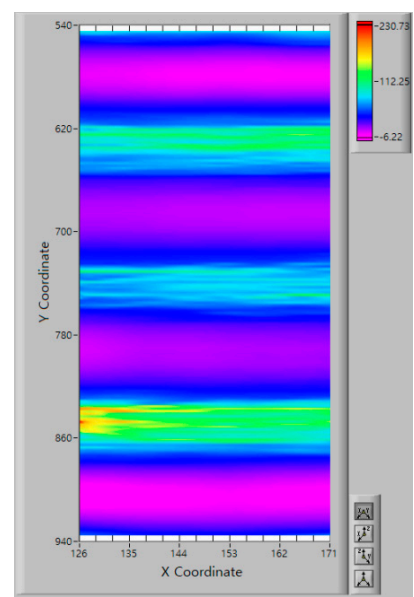

(f) 250th

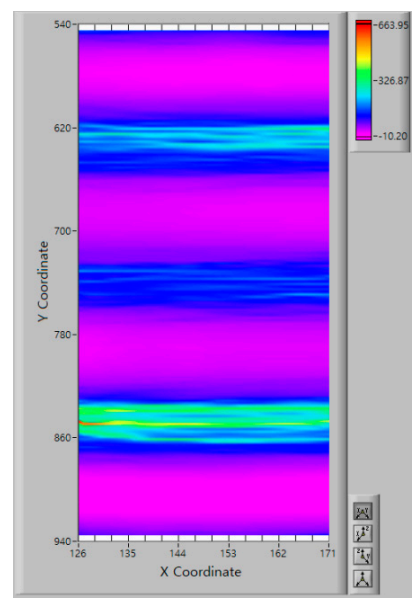

(i) 400th

Figure 18. The Y-direction displacement gradient distributions from DIC measurement. 
The position of test specimen fracture was compared with the displacement gradient distribution result of the DIC method in Figure 19. The fracture picture of the specimen is shown on the right, and the DIC displacement gradient distribution image is overlapped on the test specimen image on the left. The highest strain value line shows an exact agreement with the fracture line on the position on the specimen.

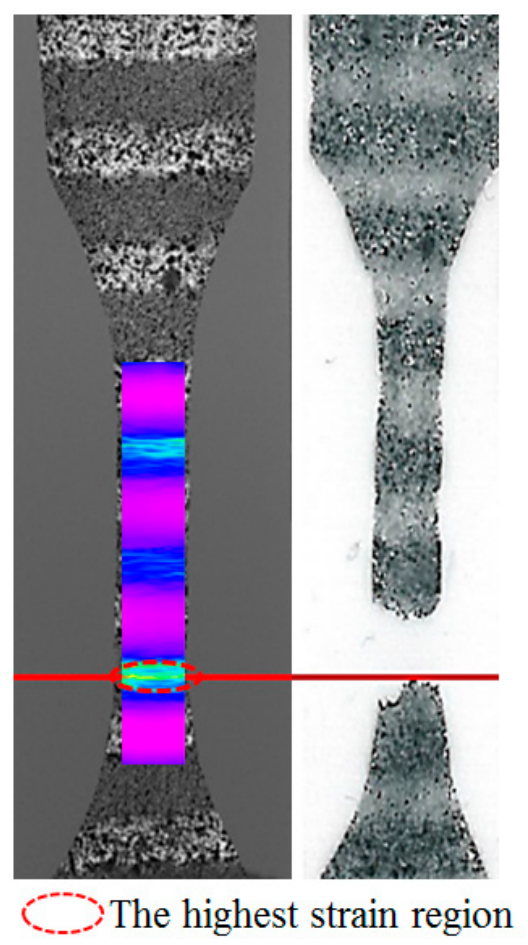

Figure 19. Comparison between the Y-direction strain measurement result with the highest strain (left) and the fracture position of specimen (right: black-and-white reversed image).

\section{Conclusions}

The nanofiber mat is used in various fields of filtering, batter or fuel cell, tissue engineering, and in drug delivery systems. Many studies on nanofiber mats have been conducted to achieve the best performance and shape for their purposes. Our non-contact measurement system with the DIC method was proposed to observe the mechanical properties of strain, especially for non-uniform material of nanofiber mats.

A novel technique was used to produce a wrinkled nanofiber mat, which is composed of a random networking part and arranged part repeatedly by electrospinning. The non-uniformity in the test specimen was increased by its structure. Finally, our measurement system adopted the DIC technique and showed whole displacement and strain distribution throughout the surface of the test specimen with time. Further research should focus on improvement in the analysis speed and measurement precision with limited configuration devices to assess the mechanical properties of such a small force-sensitive material as nanofibrous fabrics.

Author Contributions: Conceptualization, K.H.K.; Data curation, N.G.P.; Formal analysis, K.M.H.; Investigation, N.G.P.; Project administration, K.M.H.; Software, K.H.K.; Writing-original draft, N.G.P. and K.H.K.; Writing-review \& editing, K.M.H. All authors have read and agreed to the published version of the manuscript.

Funding: This work was supported by the Korea Institute of Energy Technology Evaluation and Planning (KETEP) and the Ministry of Trade, Industry \& Energy (MOTIE) of the Republic of Korea (No. 20183030029070), and this research was supported by Basic Science Research Program through the National Research Foundation of Korea (NRF) funded by the Ministry of Education (No. NRF-2020R1I1A1A01066374).

Conflicts of Interest: The authors declare no conflict of interest. 


\section{References}

1. Thavasi, V.; Singh, G.; Ramakrishna, S. Electrospun nanofibers in energy and environmental applications. Energy Environ. Sci. 2008, 1, 205-221. [CrossRef]

2. Pham, Q.P.; Sharma, U.; Mikos, A.G. Electrospinning of polymeric nanofibers for tissue engineering applications: A review. Tissue Eng. 2006, 12, 1197-1211. [CrossRef]

3. Ding, B.; Wang, M.; Wang, X.; Yu, J.; Sun, G. Electrospun nanomaterials for ultrasensitive sensors. Mater. Today 2010, 13, 16-27. [CrossRef]

4. Chronakis, I.S. Novel nanocomposites and nanoceramics based on polymer nanofibers using electrospinning process: A review. In Proceedings of the International Forum on the Advances in Materials Processing Technology, Glasgow, Scotland, 30-31 August 2005; pp. 283-293.

5. Xue, J.; Wu, T.; Dai, Y.; Xia, Y. Electrospinning and electrospun nanofibers: Methods, materials, and applications. Chem. Rev. 2019, 119, 5298-5415. [CrossRef] [PubMed]

6. Lin, Y.; Clark, D.M.; Yu, X.; Zhong, Z.; Liu, K.; Reneker, D.H. Mechanical properties of polymer nanofibers revealed by interaction with streams of air. Polymer 2012, 53, 782-790. [CrossRef]

7. Cao, Q.; Wan, Y.; Qiang, J.; Yang, R.; Fu, J.; Wang, H.; Gao, W.; Ko, F. Effect of sonication treatment on electrospinnability of high-viscosity PAN solution and mechanical performance of microfiber mat. Iran. Polym. J. 2014, 23, 947-953. [CrossRef]

8. Qiang, J.; Wan, Y.Q.; Yang, L.N.; Cao, Q.Q. Effect of ultrasonic vibration on structure and performance of electrospun PAN fibrous membrane. J. Nano Res. 2013, 233, 96-103. [CrossRef]

9. Huang, Z.M.; Zhang, Y.Z.; Ramakrishna, S.; Lim, C.T. Electrospinning and mechanical characterization of gelatin nanofibers. Polymer 2004, 45, 5361-5368. [CrossRef]

10. Ayutsede, J.; Gandhi, M.; Sukigara, S.; Micklus, M.; Chen, H.; Ko, F. Regeneration of bombyx mori silk by electrospinning. Part 3: Characterization of electrospun nonwoven mat. Polymer 2005, 46, 1625-1634. [CrossRef]

11. Lee, K.H.; Kim, H.Y.; Khil, M.S.; Ra, Y.M.; Lee, D.R. Characterization of nano-structured poly( $\varepsilon$-caprolactone) nonwoven mats via electrospinning. Polymer 2003, 44, 1287-1294. [CrossRef]

12. Petterson, D.R. Mechanics of nonwoven fabrics. J. Ind. Eng. Chem. 1959, 51, 902-903. [CrossRef]

13. Hearle, J.W.S.; Stevenson, P.J. Studies in Nonwoven Fabrics: Part IV: Prediction of Tensile Properties. Text. Res. J. 1964, 34, 181-191. [CrossRef]

14. Pan, B.; Qian, K.; Xie, H.; Asundi, A. Two-dimensional digital image correlation for in-plane displacement and strain measurement: A review. Meas. Sci. Technol. 2009, 20. [CrossRef]

15. Pan, B.; Dafang, W.; Yong, X. Incremental calculation for large deformation measurement using reliability-guided digital image correlation. Opt. Lasers Eng. 2012, 20. [CrossRef]

16. Min, H.G.; Kang, D.J.; Kim, K.J.; Park, J.H. New non-contact measurement method of deformation at tensile test of thin film via digital image correlation technique. Int. J. Precis. Eng. Manuf. 2017, 18, 1509-1517. [CrossRef]

17. Kang, M.S.; An, Y.K. Adaptive Subset-Based Digital Image Correlation for Fatigue Crack Evaluation. Appl. Sci. 2020, 10, 3574. [CrossRef]

18. Bai, R.; Jiang, H.; Lei, Z.; Li, W. A novel 2nd-oreder shape function based digital image correlation method for large deformation measurements. Opt. Lasers Eng. 2017, 90, 48-58. [CrossRef]

19. Dannemann, K.A.; Bigger, R.P.; Scott, N.L.; Weiss, C.E.; Carpenter, A.J. Application of Digital Image Correlation for Comparison of Deformation Response in Fusion and Friction Stir Welds. J. Dynamic Behavior Mater. 2016, 2, 347-364. [CrossRef]

20. Kotousov, A.; He, Z.; Fanciulli, A. Application of digital image correlation technique for investigation of the displacement and strain field within a sharp notch. Theor. Appl. Fract. Mech. 2015, 79, 51-57. [CrossRef]

21. Aytollahi, M.R.; Moazzami, M. Digital image correlation method for calculating coefficients of Williams expansion in compact tension specimen. Opt. Lasers Eng. 2017, 90, 26-33. [CrossRef]

22. Blenkinsopp, R.; Roberts, J.; Harland, A.; Sherratt, P. A Method for Calibrating a Digital Image Correlation System for Full-Field Strain Measurements during Large Deformations. Appl. Sci. 2019, 9, 2828. [CrossRef]

(C) 2020 by the authors. Licensee MDPI, Basel, Switzerland. This article is an open access article distributed under the terms and conditions of the Creative Commons Attribution (CC BY) license (http://creativecommons.org/licenses/by/4.0/). 